\title{
A New Approach to Spatial Tool Wear Analysis and Monitoring
}

\author{
Luka Čerče* - Franci Pušavec - Janez Kopač \\ University of Ljubljana, Faculty of Mechanical Engineering, Slovenia
}

The tool wear of cutting tools has a very strong impact on the product quality as well as on the efficiency of the machining processes. Despite the current high automation level in the machining industry, a few key issues prevent complete automation of the entire turning process. One of these issues is tool wear, which is usually measured off the machine tool. Therefore, its in-line characterization is crucial.

This paper presents an innovative, robust and reliable direct measurment procedure for measuring spatial cutting tool wear in-line, using a laser profile sensor. This technique allows for the determination of 3D wear profiles, which is an advantage over the currently used $2 D$ subjective techniques (microscopes, etc.). The use of the proposed measurement system removes the need for manual inspection and minimizes the time used for wear measurement.

In this paper, the system is experimentally tested on a case study, with further in-depth analyses of spatial cutting tool wear performed. In addition to tool wear measurements, tool wear modelling and tool life characterization are also performed. Based on this, a new tool life criterion is proposed, which includes the spatial characteristics of the measured tool wear.

The results of this work show that novel tool wear and tool life diagnostics yield an objective and robust methodology allowing tool wear progression to be tracked, without interruptions in the machining process or in the performance of the machining process. This work shows that such an automation of tool wear diagnostics, on a machine tool, can positively influence the productivity and quality of the machining process.

Keywords: machining process, tool wear measurement, spatial tool wear, in-line monitoring, volumetric estimator, tool life prediction

Highlights

- $\quad$ Newly developed measuring system to determine spatial cutting tool wear in-line.

- Spatial cutting tool wear measurements were performed on a case study.

- Tool wear modelling and tool life characterization has been performed.

- A new tool life criterion is proposed.

\section{INTRODUCTION AND STATE OF THE ART}

The tool wear of cutting tools has a very strong impact on product quality as well as on the efficiency of machining processes overall. Despite the current high automation level in the machining industry, a few key issues prevent complete automation of the entire turning process. One of these issues is tool wear, which is usually measured off the machine tool and is still done by hand under a toolmaker's microscope. There is no any industry wide procedure for automating the process of measuring wear. Furthermore, such conventional wear measurement requires stopping the automated turning, removing the tool, measuring the tool and putting the tool back to the holder, which is a considerable time loss relative to the tool's life. Therefore, the in-line characterization of cutting tool wear is crucial for cutting cycle times and costs, as well increasing the overall efficiency of the machining process.

This paper presents an innovative, robust and reliable direct measuring procedure for measuring spatial cutting tool wear in-line using a laser profile sensor. This technique allows 3D wear profiles to be determined, which is an advantage over the currently used 2D subjective techniques (microscopes, etc.). The use of the proposed measurement system removes the need for manual inspection and minimizes the time used for wear measurement. A tool life characterization is also performed. Based on this, a new tool life criterion is proposed that includes the spatial characteristics of the measured tool wear. In the next three subsections, extensive state reviews are performed.

\subsection{Tool Wear Characterization Review}

The damages to a cutting tool are the consequence of the stress state and thermal loads on the tool surfaces, which in turn depend on the cutting mode, i.e. turning, milling or drilling, cutting parameters and the cooling/ lubrication conditions.

During machining, the cutting tool wear mechanisms and their rates are very sensitive to changes in the cutting operation and the cutting conditions. To minimize machining costs, one must not only to find the most suitable cutting tool and work material combination for a given machining operation, but also reliably predict the tool life and also the tool changing/replacement protocol. 
Tool wear mainly occurs at the rake and flank face. Flank wear is caused by friction between the flank face of the cutting tool and the machined workpiece surface and leads to loss of the cutting edge. Therefore, flank wear affects the dimensional accuracy and surface finish quality of the product. In practice, flank wear is generally used as the cutting tool wear criteria. When critical value of tool wear has been reached, the cutting tool is assumed to have reached its tool life. This point should be placed before but close to the moment when the cutting tool fails due to excessive stresses and thermal alterations. To avoid this, the cutting tool must be replaced before reaching its critical limit. In practice, the preferred cutting tool life criteria is the tool-flank wear threshold. However, even though the wear should progress gradually and should thus be easily monitored, tool wear is hard to predict due to uncertainties in the machining process. Therefore, to robustly define the tool-changing protocol in NC (numeric control) programs, the inline tool wear measurement is inevitable [1] and [2].

In practice, some directly measured dimensional characteristics and criteria of typical wear patterns, i.e. crater, flank wear, and depth-of-cut notch wear at the extremities, for HSS (high speed steels), carbide and ceramics tools, are standardized in ISO 3685 [3], as shown in Fig. 1.

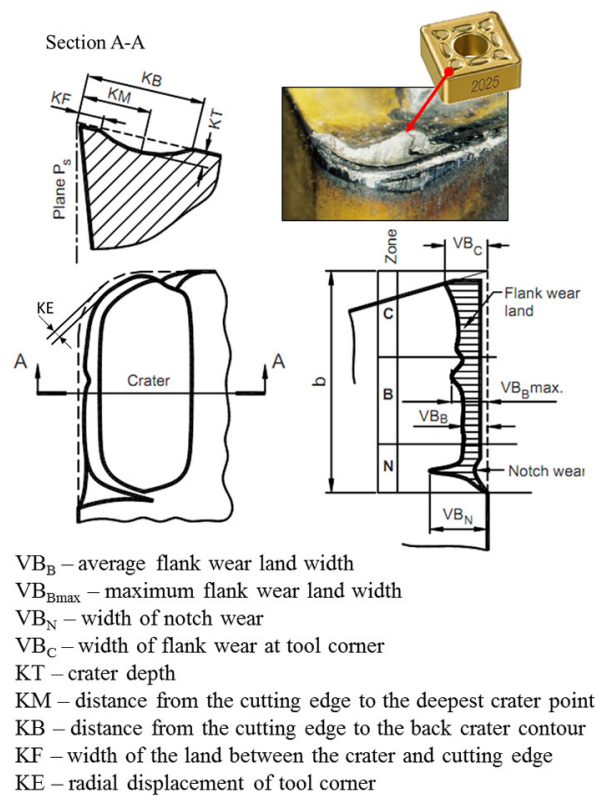

Fig. 1. Typical wear pattern according to ISO 3685

The process of cutting tool wear consists of three characteristic parts: the initial (running-in) period, the longest uniform (progressive) wear period and the accelerated wear period leading often to catastrophic failure [1].

The machining process needs to be, on the one hand, stopped at the right time to prevent undesired consequences of the tool wear, such as increases in cutting forces, vibrations, noise, and temperature in the cutting zone, as well as deviation of part dimensions and surface quality from the point of view of respective tolerance values, while on the other hand, the tool should be replaced as late as possible to increase efficiency and decrease tooling costs.

In reality, several wear mechanisms occur simultaneously, although any one of them may dominate the process. They can be qualitatively identified as mechanical, thermal and adhesive. Mechanical types of wear, which include abrasion, chipping, early gross fracture and mechanical fatigue, are basically independent of temperature. Thermal loads appear with plastic deformation, thermal diffusion and oxygen corrosion as their typical forms, and increase drastically at high temperatures, thus accelerating the tool failure by causing easier tool material removal (by abrasion or attrition) [4].

At high cutting speed, temperature-activated wear mechanisms including diffusion (solution wear), chemical wear (oxidation and corrosion wear), and thermal wear (superficial plastic deformation due to thermal softening effect) occur. By contrast, at lower cutting speeds adhesive and abrasive wear are the most significant types of wear.

ISO 3685 notes that the type of tool wear is difficult to determine when machining with grooved tools. Ee et al. [5] found that the tool wear pattern on a worn grooved tool insert is influenced by the threedimensional chip-flow and by the complex chipgroove configurations. They also found that some grooved tools fail long before the major flank wear $\left(V B_{B}\right)$ reaches its failure criterion in many cases. It is also shown, that grooved tools demonstrate toolfailure as a result of concurrent multiple tool wear parameters. This confirms that the tool wear, or rather tool life, is significantly affected by the combined effects of cutting conditions and chip-groove configurations. This also answers the question as to why several new measurable parameters have been proposed for tool wear in machining with grooved tools (Fig. 2) [5]. From the grooved tools wear parameters, it can be seen that the wear regions in grooved tools can be very specific, such as the notch, etc. However, in general they can be divided into three major wear regions. These are: (a) the edge wear region, (b) the land and secondary face wear region, and (c) the backwall wear region (Fig. 2). 


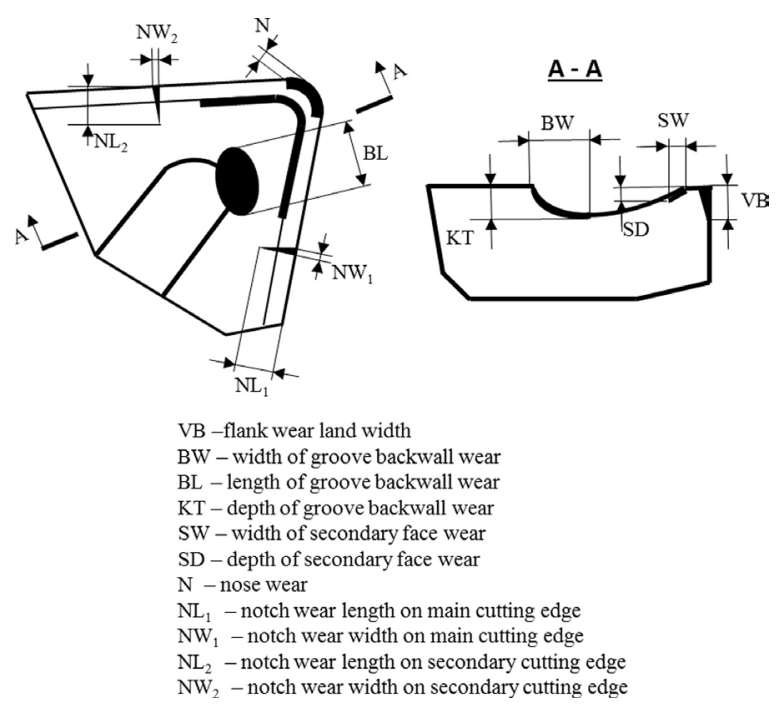

Fig. 2. Measurable tool wear parameters in grooved tools

\subsection{Tool Wear Measurement Review}

Tool wear can be measured using direct measuring techniques or estimated by indirect measuring techniques [6] and [7]. In indirect measuring techniques, tool wear is estimated using other more measurable machining process variables such as cutting force, surface finish, acoustic emission, vibrations, energy consumption, temperature, etc. [8]. A survey of the literature indicates that a variety of approaches have been applied to tool wear prediction [9] to [12]. Conversely, with direct measuring techniques, condition monitoring is carried out by analysing the change in geometry of the cutting tool. Usually these techniques can be taken only between two sequential machining runs, because the major flank of the tool is not visible during actual machining. Direct tool condition monitoring techniques can be divided into two-dimensional and three-dimensional techniques. Additionally, they can be divided into measurements made directly on the machine tool or outside it (using a microscope, etc.).

Kurada and Bradley [13] have designed a system consisting of a fiber-optic light source to illuminate the tool and a CCD camera, which is used in combination with a high resolution video zoom microscope. The resolution in the captured image was approximately $3 \mu \mathrm{m}$ per pixel. Images are captured orthogonally to the flank face. The actual wear region identification and measurement relies on the specular reflection of the wear area from the fiber-optic lights. Identification of the tool wear area is performed in $2 \mathrm{D}$, through the wear area reflection.
Lanzetta [14] has a different approach to the problem. Using two cameras, a grey-scale image is taken from the nose of the tool and image of the tool silhouette is taken from the top of the tool. The silhouette is taken with a back-light and the tool nose is directly illuminated. Images are also taken with a directional light from the top of the tool to detect crater wear. Flank wear is measured from the silhouette image. The silhouette of the worn tool is compared to the silhouette of the unused tool, which gives an estimate of the tool flank wear. Measurement error is reported to be less than $5 \%$. Niranjan Prasad and Ramamoorthy [15] measured the crater wear using stereo vision. Stereo vision is not achieved by using two cameras but with the tool moving between two images taken with the same grey-scale camera. Resolution is $12 \mu \mathrm{m} \times 10 \mu \mathrm{m}$ per pixel. The depth and width of the crater wear is measured and the measurements can be made accurately. However, the images of the tool are taken outside the turning machine and no method for automatically measuring the flank wear is presented.

On the other hand, Jurkovic et al. [16] used structured light from a laser diode to capture elevation information from the tool surface. A monochrome CCD camera was used to capture the images with a halogen light. The resolution of the image was approximately $3 \mu \mathrm{m}$ per pixel. Flank wear can be measured as well as crater wear using the elevation information. The system was combined with a CNC lathe. Additionally, Devillez et al. [17] shows that white light interferometry is a useful tool for measuring cutting insert crater wear. The measurement methodology allows examination of all aspects of crater wear after the metal cutting process, although this technique does not permit in-line tool crater measurement and flank wear measurement. Dawson and Kurfess [18] present a novel method for quantifying tool wear using three-dimensional computational metrology that is also based on white light interferometry. The presented measurement technique allows measurement of flank and crater wear. Furthermore, a technique was developed to measure the deviations between the three-dimensional tool data and an 'ideal' version of an unworn cutting tool. The calculated deviations were then used to define the tool wear volume. Wang et al. [19] employ a phase shifting method using fringe patterns to measure crater wear by constructing a $3 \mathrm{D}$ map of the tool insert. Four fringe patterns with various phaseshifts are projected onto the rake face of the tool upon which four grey-level images are captured. With appropriate setup, the system can be used for on-line 
crater wear measurement in industry, but the accuracy level is limited. A combination of the fringe projection system and the white light interferometry is used by Weckenmann and Nalbantic [20].

The main disadvantages of the described methods are the inability to measure wear profiles in depth (three-dimensional geometry of crater wear $-K T$, etc.) and/or that they cannot be robustly used directly in the machine tool. To perform the measurement with these methods, the cutting insert should be removed from the machine tool. This causes time loss and possible problems with the accuracy of subsequent processing. This paper presents a novel method belonging to direct measuring method of determining of cutting tool wear. This method offers the possibility of threedimensional tool wear measurement directly on the machine tool, without the need to remove cutting inserts from the tool holder (machine tool).

\subsection{Tool Life Assessment Review}

Flank wear of cutting tools is often selected as the tool life criterion because it determines the diametric accuracy of machining, as well as its stability and reliability [21]. According to the ISO 3685:1993 [3], the assessment of flank wear is determined by its direct measurement. Flank wear is considered using an aged Taylor's tool life equation having a phenomenological nature. The Taylor Tool life estimation is based on experimental data that are gathered by measuring the time until the tool life criterion is fulfilled using several different cutting speeds. Based on this experimental set, a curve (regression model) representing the tool life can be constructed. The drawback is that it describes just the linear section of the tool life curve. Additionally, Taylor's basic equation does not include the effect of cutting feed and is limited to a certain range of speeds. It also does not give information about the tool wear at any particular time $t$ during turning. Even though an improved Taylor model exists that includes both feed and depth of cut, but they still just cover the tool life, not the wear at particular times.

An additional problem of such a model is that it is constructed based on tool wear measurements performed by the operator, etc. These assessments are subjective and insufficient. They do not include the tool geometry (the flank angle, the rake angle, the cutting edge angle, etc.) so they are not suitable for comparing cutting tools having different geometries. They do not include the cutting regime and thus do not reflect the real amount of work material removed by the tool during the time over which the measured flank wear is achieved [21].

The selection of these characteristics depends upon the particular objective of a tool wear study. Most often, dimensional accuracy dictates this selection, i.e. the need to manufacture parts within the tolerance limits assigned for tool wear. As such, the tool life defined by this criterion may be referred to as dimension tool life. Dimension tool life can be characterized by the time within which the tool works without adjustment or replacement $\left(T_{c-l}\right)$; by the number of parts produced $\left(N_{p-l}\right)$; by the length of the tool path $\left(L_{c-l}\right)$; by the area of the machined surface $\left(A_{c-l}\right)$ and by the linear relative wear $\left(h_{l-r}\right)$ [21]. All these characteristics listed are particulars and thus, in general, do not allow for the optimal control of cutting operations, comparison of different cutting regimes, assessment of different tool materials, etc. For example, dimensional tool life is of little help if one needs to compare cutting tools that work at different cutting speeds and feeds and/or when the widths of their flank wear land are not the same. The problem lies in the complex cutting tool surface geometries as well as high stochastic behaviour of the tool wear from the point of view of aggression and location. Therefore, the combination of the dimensional wear rate with the relative surface wear and the specific dimensional tool life are much more general characteristics to be used in metal cutting tests conducted everywhere from the research laboratory to shop floor level. A new 3D tool wear based estimation is presented in Section 2.

\section{NEWLY DEVELOPED MEASUREMENT SYSTEM}

The newly developed measuring system (Fig. 3) consists of a high-accuracy 2D laser displacement sensor Keyence LJ-G015 with a proper controller Keyence LJ-G5001 [22], a motorized linear translation stage Standa 8MT173-DCE2 and a LabVIEW application developed for process control.

The measurement range of the 2D laser displacement sensor Keyence LJ-G015 is in Z-axis (height) $\pm 2.6 \mathrm{~mm}$ and $7.0 \mathrm{~mm}$ in $\mathrm{X}$-axis at the reference distance. The repeatability in the Z-axis is $0.2 \mu \mathrm{m}$ and $2.5 \mu \mathrm{m}$ in the X-axis. For linear positioning of the measurement head, a motorized linear translation stage is used with a minimal incremental motion of $0.1 \mu \mathrm{m}$ and bi-directional repeatability of $0.4 \mu \mathrm{m}$ [23].

With movement of the profile sensor across the cutting tool and the support of the developed software (LabVIEW application), the profile data are grabbed and prepared in a matrix form for further evaluation and analysis. A laser displacement sensor measures 
the distance from the measurement head to the points projected on the measured object. In this way the $\mathrm{Z}$-coordinates of the point cloud are measured. The $\mathrm{X}$-coordinate is defined by the specification of the laser displacement sensor [22], while the Y-coordinate represents linear stage feed direction.

While the relative position/orientation of the measuring head has a significant influence on the measurements, the analysis of its orientation has been experimentally and empirically analysed in one of our previous works [24]. The accuracy was determined to reach $\pm 8 \mu \mathrm{m}$. The measurement system was mounted on Mori Seiki SL-153 CNC lathe as shown in Fig. 3. This allows a quick measurement of tool wear on the machine tool itself. Between two machining operations, the average measuring procedure can be performed in approximately $20 \mathrm{~s}$, without stopping the machining process.

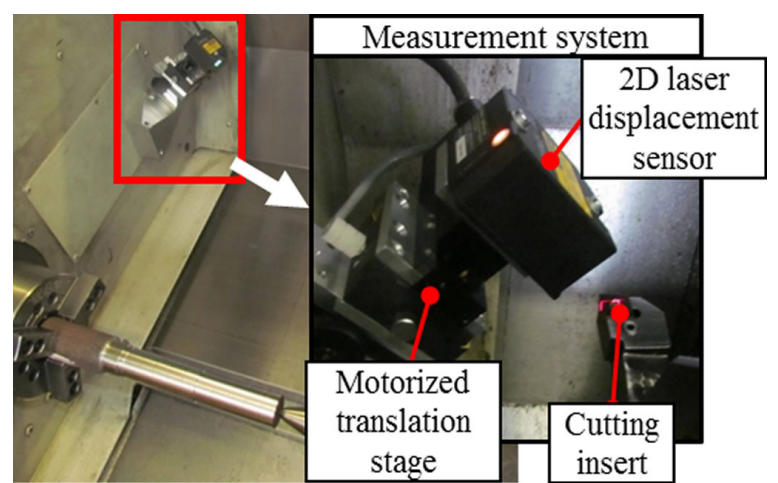

Fig. 3. Measurement system mounted on a Mori Seiki machine tool

Thus, we can take a measurement that includes far more information about tool wear, without having to remove the cutting inserts from the holders, which would be necessary if we were to measure tool wear on a toolmaker's microscope.

\section{TOOL LIFE PREDICTION FOR GROOVED CUTTING INSERTS}

Tool life prediction in grooved tools involves simultaneously occurring multiple wear parameters, as presented in Fig. 2 (wear on flank, wear on rake, etc.). However, there are no universally accepted standards for tool life prediction in grooved tools. The ISO 3685 based criterion, established for flat-faced tools, is usually not implementable on grooved tools. The geometry of the cutting tool significantly affects tool life, as the geometry defines the magnitude and direction of the cutting force and its components, the sliding velocity at the tool-chip interface, the distribution of the thermal energy released in machining, the temperature distribution in the cutting edge, etc. [21]. Therefore, a new tool life prediction method is presented based on the rate of cutting tool geometry change and consequent change in the stresses at the cutting edge.

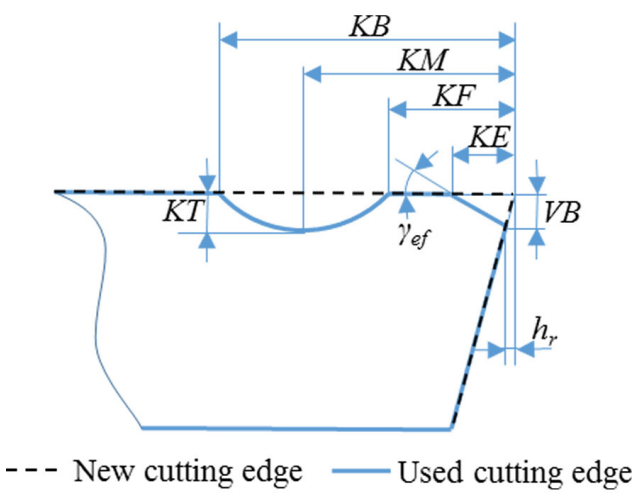

Fig. 4. Measured cutting tool wear geometry

The greatest impact on prediction of the tool life for finishing operations is the radial wear $h_{r}$ (Fig. 4). Thus, we can say that the cutting tool is useful until the radial wear $h_{r}$ exceeds the prescribed tolerance of the workpiece. With the previously presented measurement system, current radial wear $h_{r}$ can be measured directly on the machine tool. In this way we can control, measure and predict the cutting tool life for finishing operations.

In roughing operations, productivity is important (i.e. material removal rate), so the tool breakage is under consideration. For this purpose the influence of mechanical load on the rake face of the cutting insert will be simulated using the finite element method (FEM). Tamizharasan and Kumar [25] use FEM for simulating the effect of tool geometry on flank wear, surface roughness and cutting forces. In our case, the $3 \mathrm{D}$ model of the cutting insert is defined on the basis of measurements results $\left(K T, V B, K E\right.$ and $\left.\gamma_{e f}\right)$ performed in a case study. The mechanical pressure distribution on the rake face is applied based on the Zorev model [26]. The pressure decreases nonlinearly from the maximum value at the cutting edge to zero at the end of chip-tool contact zone (where the chip separates from the rake face). Apart from the model of contact load distribution on the tool faces, the contact load also depends on the contact area of the tool with the chip and the workpiece. On the rake face, the contact area depends on the contact length between the chip and tool rake face, $l_{c r}$, as shown in Fig. 5, and chip width. The length can be measured from the rubbing marks on the rake face, which can be 
seen from the 3D wear measurements. The case study will be shown in the next section.

As a benefit of these FEM simulations, stress analyses show how changes in the geometry (wear) bring the tool to the stress limit/structure breakage. Based on this, the tool life can be predicted and with it the undesired tool breakage in real machining operations.

(a)
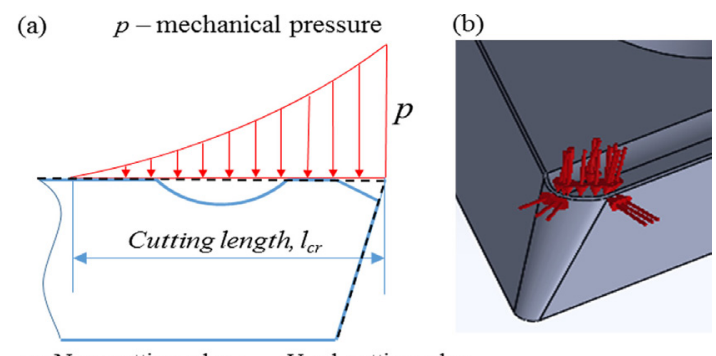

Fig. 5. a) mechanical pressure distribution on the cutting tool edge, and b) 3D model of cutting insert with pressure distribution on the rake face

As a proof of the proposed concept, the measurement system presented in Section 1 was tested in a machining environment. The results of a case study were analysed as described above and are presented in the next section.

\section{CASE STUDY AND RESULTS}

The presented measurement system has been tested on a case study of bearing steel machining $(100 \mathrm{Cr} 6$ AISI52100) performance determination. A bar shaped workpiece with diameter $40 \mathrm{~mm}$ and length $290 \mathrm{~mm}$ was machined. Machining tests were conducted on a Mori Seiki SL-153 turning machine. Commercially available Sumitomo DCGT 11T304 R-FX cutting inserts, grade ACZ310, were used with SDCJR 2020K11 tool-holder. All the machining experiments were performed dry, while the cutting parameters have been defined according to the manufacturer's recommendations: $a_{p}=1 \mathrm{~mm}, v_{c}=250 \mathrm{~m} / \mathrm{min}$ and $f=0.12 \mathrm{~mm} / \mathrm{rev}$. To follow the progress of the wear, the sequential longitudinal workpiece turning operations were performed on $20 \mathrm{~mm}$ length intervals. The result of the corresponding tool wear progress is presented in Fig. 6. The measurement itself is executed in approximately 20 seconds, grabbing the $6 \mathrm{~mm} \times 3.5 \mathrm{~mm}$ area, with a grid size of $0.01 \mathrm{~mm} \times 0.005 \mathrm{~mm}(\Delta X \times \Delta Y)$.

To determine tool wear progress, six repeated measurements were performed. The first picture shows the new (unworn) cutting insert, while the sixth picture show the critical wear that occur on the rake face of the cutting tool after 7.4 minutes of machining. The colour on those plots corresponds for the wear magnitude. Red color shows the presence of BUE (build up edge), while the blue color shows the actual wear. Nevertheless, the BUE regions were not dominant. Furthermore, from the result it can be seen that abrasive, adhesive and diffusion wear occurred on the cutting edge. Abrasive and diffusion wear can be observed on the rake face (region of blue colour), while adhesive wear is seen in the growing region of yellow colour. The progression of crater wear on rake face and chipping of cutting edge can also be observed (Fig. 6, darker blue zone on cutting edge). Observing the rake face crater wear depth formation, with a growing region of darker blue colour, high temperatures in cutting area are suspected.

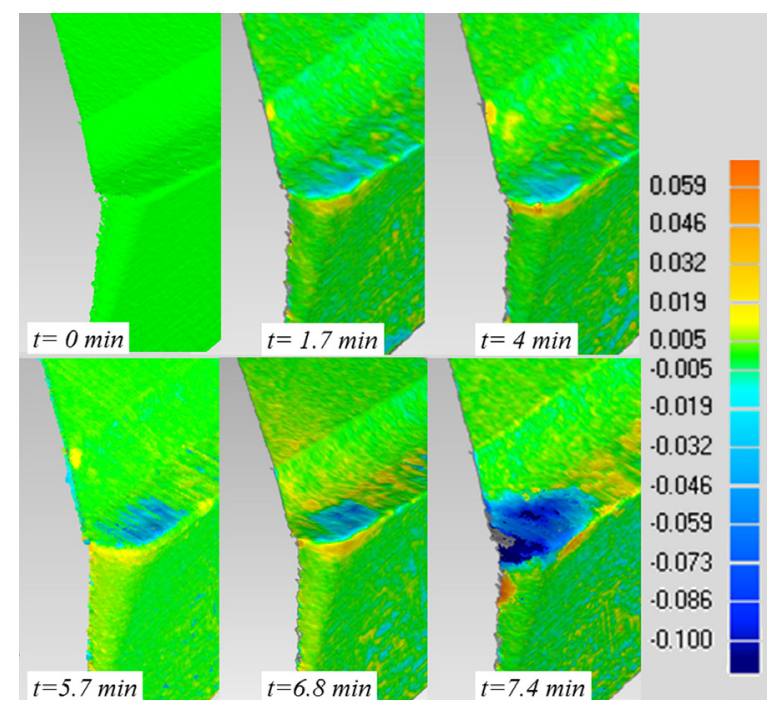

Fig. 6. 3D deviation results (new vs. worn cutting tools)

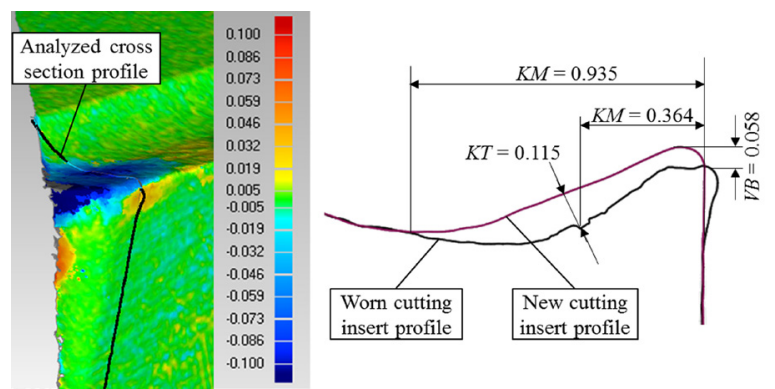

Fig. 7. Measurement of typical wear patterns, according to ISO 3685 , on a cross section profile, $0.5 \mathrm{~mm}$ from secondary flank face after 7.4 min of cutting

For analysis of the extent and shape of the wear, an example of a cross section perpendicular to the primary flank face is shown and analysed in Fig. 7. 
The wear corresponds to the 7.4 min of machining. The depth of flank wear is clearly visible from the comparison of cutting inserts cross-sections profiles (new vs. worn). Fig. 7 shows that with the use of the presented measurement system, the extent of the wear formation can be precisely determined. The depth of the crater for this particular case is $K T=0.115 \mathrm{~mm}$ and the flank wear extends to a depth $V B=0.058 \mathrm{~mm}$.

The 3D deviation results showed that the maximum wear occurs $0.5 \mathrm{~mm}$ from the secondary flank face. Therefore, these profiles have been analysed and the results of flank wear land width $(V B)$ and total wear volume $\left(V_{\text {Wear }}\right)$ as a function of cutting time are presented in Fig. 8.

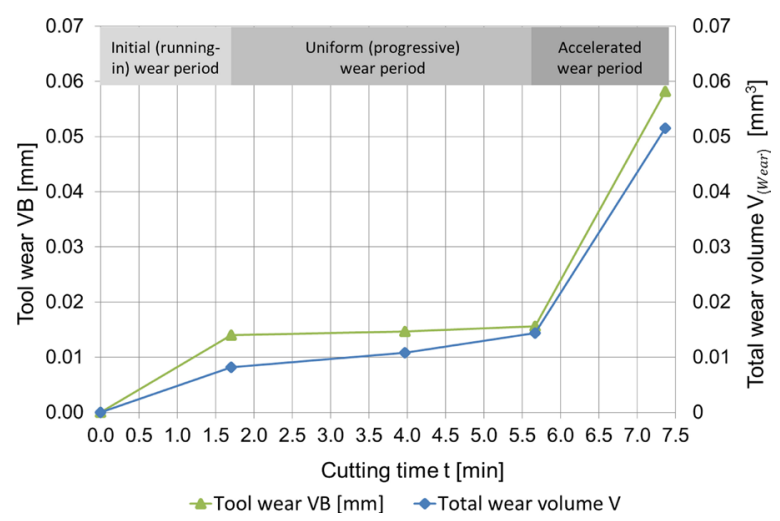

Fig. 8. Flank wear land width (VB) for cross section profile $0.5 \mathrm{~mm}$ from the secondary flank face and total wear volume $\left(V_{\text {Wear }}\right)$ as function of cutting time $t$

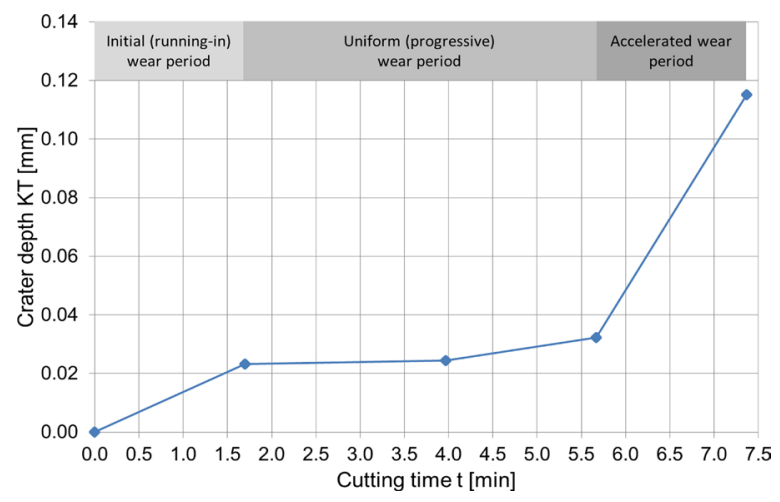

Fig. 9. Maximum crater depth (KT) as a function of cutting time $t$ for the cross section profile $0.5 \mathrm{~mm}$ from secondary flank face

Maximum crater depth $(K T)$ as a function of cutting time is shown in Fig. 9. In all cases, three characteristic parts are observed: the initial (runningin) period (up until $1.5 \mathrm{~min}$ ), the longest uniform (progressive) wear period (from $1.5 \mathrm{~min}$ to $5.5 \mathrm{~min}$ ) and the accelerated wear period (from $5.5 \mathrm{~min}$ on).
The results confirm that observing just the $V B$ is not sufficient for tool life prediction. Higher wear than $V B$ is observed on the rake face (although values are significantly smaller than $K T$ ). The $V B$ will result in higher cutting forces and missing tolerances, while $K T$ will cause cutting tool breakage.

In practice, the most important consideration in selecting cutting tools and cutting conditions is tool life $(T) . T$ is defined as the time when the measured wear levels exceed a predefined threshold. A standard measure of tool life is the time to develop a flank wear length $V B_{B}$ of $0.3 \mathrm{~mm}$ or $V B_{B \max }$ of $0.6 \mathrm{~mm}$, in case of cemented carbides. Standard ISO 3685:1993 also recommends a maximum value of $K T\left(K T_{\max }\right)$. It can be empirically calculated via following equation [2]:

$$
K T_{\max }=0.06+0.3 \cdot f,
$$

where $f$ is feed. For the cutting parameters used, the $K T_{\max }$ is $0.096 \mathrm{~mm}$. From the results presented in Fig. 9 it is apparent that $K T$ is critical, while the critical value for $V B$ is not reached (Fig. 8) $(V B=0.06 \mathrm{~mm}$ after 7.5 min of machining). However, this empirical $K T_{\max }$ equation does not include a lot of important parameters in machining (material, depth of cut, etc.) and is questionable. Therefore, this paper also aims to present a new approach in tool life prediction using FEM simulations. For this purpose, geometry data from cross-section profiles of the worn cutting inserts have been used to build an accurate 3D model of the cutting edge. This model has been used for stress analysis. The maximum pressure $p=0.95 \mathrm{GPa}$ has been calculated from cutting forces. This has been performed with a back calculation of online measured cutting forces. The cutting tool material properties presented in Table 1 were found in the literature [27] and [28] and used in this work.

Table 1. Cutting tool material properties

\begin{tabular}{lr}
\hline Elastic modulus & $600000 \mathrm{~N} / \mathrm{mm}^{2}$ \\
\hline Poisson's ratio & 0.225 \\
\hline Shear modulus & $263000 \mathrm{~N} / \mathrm{mm}^{2}$ \\
\hline Mass density & $14.5 \mathrm{~kg} / \mathrm{m}^{3}$ \\
\hline Tensile strength & $450 \mathrm{~N} / \mathrm{mm}^{2}$ \\
\hline Compressive strength & $6000 \mathrm{~N} / \mathrm{mm}^{2}$ \\
\hline
\end{tabular}

The results of the FEM simulation are presented in the Fig. 10. In Fig. 10a, the results of stress analyses of the new cutting insert are presented, while Fig. 10b presents results for the critically worn insert. The wear corresponds to the $7.4 \mathrm{~min}$ of machining. The maximal stress for a new insert (a) is $7.3 \times 10^{8} \mathrm{~N} / \mathrm{m}^{2}$ 
(yellow zone), while for the worn inserts (b) it is much bigger $1.1 \times 109 \mathrm{~N} / \mathrm{m}^{2}$ (red zone).

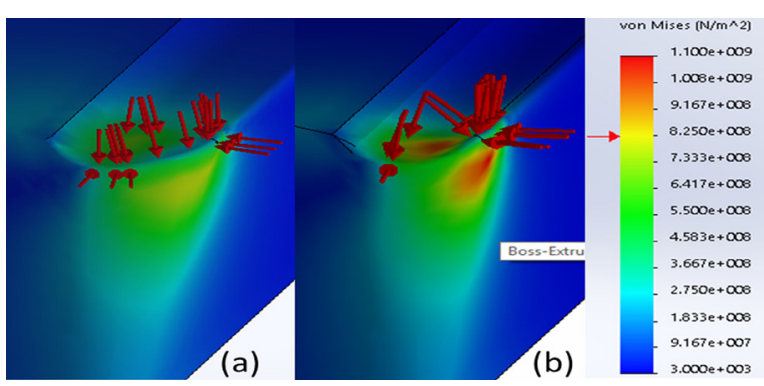

Fig. 10. FEM simulation results for a) new (unworn) and b) worn cutting insert

The presented results showed that FEM simulations are in good correlation with the experimental data presented in Fig. 8 (total volume $\left.V_{\text {Wear }}\right)$ and Fig. $9(K T)$.

The stress at the cutting tool edge increases drastically when crater wear becomes significant (from $5 \mathrm{~min}$ to the end), as can be seen in Fig. 11. This happens due to the notch effect. By increasing the depth of crater wear, the cross-section of the cutting edge became smaller, and therefore the stress in the material increases. This leads to catastrophic tool fracture (breakage) when the stresses became higher than the material yield strength. The cutting time limit before the breakage occurs defines the cutting tool life.

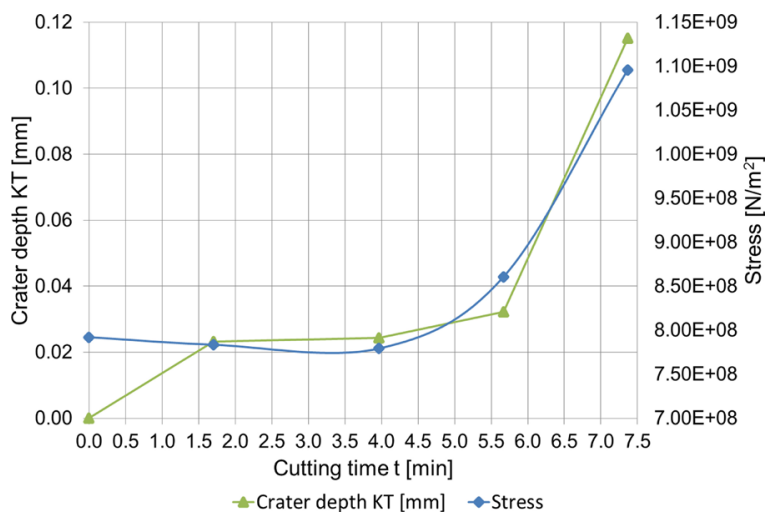

Fig. 11. FEM simulated stress and crater depth $K T$ as function of cutting time t for cutting tool edge

On the other hand, maximal crater depth $K T$ can be predicted from the yield strength and actual stress. With maximal $K T$ thus defined the presented spatial measurement system can be used for the robust control of the process and its efficiency. Going a step further, this procedure can also cover the $K T$ and $V B$ combination (or any other wear mechanism), where the cutting tool breakage can be foreseen.

\section{CONCLUSIONS}

This paper presents an innovative, robust and reliable direct measuring procedure for determining spatial cutting tool wear in-line on machine tools. The technique allows for the determination of 3D wear profiles, an advantage over the currently used 2D subjective techniques (microscopes, etc.). The use of the proposed measurement system removes the need for manual inspection and minimizes the time used for wear measurement. The measurement data thus obtained are actually realistic 3D models of the cutting tool/wear, where we can clearly see what the existing conditions of the cutting tool are. With information on three-dimensional deviations, this method outperforms traditional 2D deviation methods in accuracy, efficiency and reliability.

Besides tool wear, this work also upgrades existing tool life methodologies with spatial tool wear information. A new methodology for tool life prediction, based on FEM stress simulation is presented. Because it is known that the geometry of the cutting tool directly affects tool life, cross-section profiles of the worn cutting inserts have been used to build an accurate 3D model of the cutting edge. For this, the measurement system has been experimentally tested on a case study machining $100 \mathrm{Cr} 6$ bearing steel on a CNC lathe. The cutting tool wear has been measured directly on the machine tool, without the need to remove the cutting insert from the machine tool and analyse it under the microscope. In addition to the presented conventional results $(V B, K T)$, this new spatial tool wear measuring system, allows tool wear volume $V_{\text {Wear }}$ to be measured and analysed.

A constructed FEM model was run to predict tool life. This model compared unworn and worn insert geometries and used stress analysis for the FEM. The mechanical loading was same for worn and unworn inserts and was experimentally defined. From the obtained stress results, the cutting time limit before breakage occurs (tool life) can be more accurately defined/predicted. These predictions for the case study are also correlated with the fractures occurring on the cutting tool. The results show that FEM simulations can be used to determine the time limit before fracturing of the cutting tool/tool life.

The results of this work show that novel tool wear and tool life diagnostics represent an objective and robust method of tracking tool wear progress, without interrupting the machining process, as well 
as the performances of the machining process itself. Additionally, the tool life/tool fracturing can be robustly predicted in-line. To summarize, our work shows that the automation of tool wear diagnostics inline on a machine tool can beneficially influence the productivity, efficiency and quality of the machining process.

\section{REFERENCES}

[1] Cheng, K. (2009). Machining Dynamics, Fundamentals, Applications and Practices. Springer, London.

[2] Kopač, J. (2008). Machining: Theoretical Basis and Technological Information. Faculty of Mechanical Engineering, Ljubljana. (in Slovene)

[3] ISO 3685 (1993): Tool-Life Testing with Single-Point Turning Tools. International Organization for Standardization, Geneva.

[4] Grzesik, W. (2008). Advanced Machining Processes of Metallic Materials. Elsevier B.V., Amsterdam.

[5] Ee, K.C., Balaji, A. K., Jawahir, I.S. (2003). Progressive tool wear mechanisms and their effects on chip-curl/chip-form in machining with grooved tools: an extended application of the equivalent toolface (ET) model. Wear, vol. 255, no. 7-12, p. 1404-1413, D0l:10.1016/S0043-1648(03)00112-1.

[6] Kurada, S., Bradley, C. (1997). A review of machine vision sensors for tool condition monitoring. Computers in Industry, vol. 34, no. 1, p. 55-72, D0l:10.1016/S0166-3615(96)000759.

[7] Dutta, S., Pal, S. K., Mukhopadhyay, S., Sen, R. (2013). Application of digital image processing in tool condition monitoring: A review. CIRP Journal of Manufacturing Science and Technology, vol. 6, no. 3, p. 212-232, D0l:10.1016/j. cirpj.2013.02.005.

[8] Siddhpura, A., Paurobally, R. (2013). A review of flank wear prediction methods for tool condition monitoring in a turning process. The International Journal of Advanced Manufacturing Technology, vol. 65, no. 1-4, p. 371-393, Dol:10.1007/s00170012-4177-1.

[9] Dimla Snr, D.E. (2000). Sensor signals for tool wear monitoring in metal cutting operations-a review of methods. International Journal of Machine Tools and Manufacture, vol. 40, no. 8, p. 1073-1098, DOI:10.1016/s0890-6955(99)00122-4.

[10] Govekar, E., Gradišek, J., Grabec, I. (2000). Analysis of acoustic emission signals and monitoring of machining processes. Ultrasonics, vol. 38, no. 1-8, p. 598-603, D0l:10.1016/S0041624X(99)00126-2.

[11] Teti, R., Jemielniak, K., O'Donnell, G., Dornfeld, D. (2010). Advanced monitoring of machining operations. CIRP Annals - Manufacturing Technology, vol. 59, no. 2, p. 717-739, DOI:10.1016/j.cirp.2010.05.010.

[12] Venkata Rao, K., Murthy, B.S.N., Mohan Rao, N. (2013). Cutting tool condition monitoring by analyzing surface roughness, work piece vibration and volume of metal removed for AISI 1040 steel in boring. Measurement, vol. 46, no. 10, p. 4075-4084, D0I:10.1016/j.measurement.2013.07.021.
[13] Kurada, S., Bradley, C. (1997). A machine vision system for tool wear assessment. Tribology International, vol. 30, no 4, p. 295-304, DOI:10.1016/S0301-679X(96)00058-8.

[14] Lanzetta, M. (2001). A new flexible high-resolution vision sensor for tool condition monitoring. Journal of Materials Processing Technology, vol. 119, no. 1-3, p. 73-82, Dol:10.1016/S0924-0136(01)00878-0.

[15] Niranjan Prasad, K., Ramamoorthy, B. (2001). Tool wear evaluation by stereo vision and prediction by artificial neural network. Journal of Materials Processing Technology, vol. 112, no. 1, p. 43-52, D0I:10.1016/S0924-0136(00)00896-7.

[16] Jurkovic, J., Korosec, M., Kopac, J. (2005). New approach in tool wear measuring technique using $\mathrm{CCD}$ vision system. International Journal of Machine Tools and Manufacture, vol. 45, no. 9, p. 1023-1030, D0l:10.1016/j. ijmachtools.2004.11.030.

[17] Devillez, A., Lesko, S., Mozer W. (2004). Cutting tool crater wear measurement with white light interferometry. Wear, vol. 256, no. 1-2, p. 56-65, D0l:10.1016/S0043-1648(03)003843.

[18] Dawson, T.G., Kurfess, T.R. (2005). Quantification of tool wear using white light interferometry and three-dimensional computational metrology. International Journal of Machine Tools and Manufacture, vol. 45, no. 4-5, p. 591-596, D0l:10.1016/j.ijmachtools.2004.08.022.

[19] Wang, W.H., Wong, Y.S., Hong, G.S. (2006). 3D measurement of crater wear by phase shifting method. Wear, vol. 261, no. 2 , p. 164-171, D0l:10.1016/j.wear.2005.09.036.

[20] Weckenmann, A., Nalbantic, K. (2003). Precision measurement of cutting tools with two matched optical 3D-sensors. CIRP Annals - Manufacturing Technology, vol. 52, no. 1, p. 443-446, D0l:10.1016/S0007-8506(07)60621-0.

[21] Astakhov, V.P. (2004). The assessment of cutting tool wear. International Journal of Machine Tools \& Manufacture, vol. 44, no. 6, p. 637-647, D0l:10.1016/j.ijmachtools.2003.11.006.

[22] Keyence (2010). High-accuracy 2D Laser Displacement Sensor. Keyence.

[23] Standa. Translation Stage with DC motor, from http://www. standa.lt, accessed on 2014-21-2

[24] Cerce, L., Pusavec, F., Dugar, J., Kopac, J. (2013). Further development of the spatial cutting tool wear measurement system. Journal of Production Engineering, vol. 16, no. 2, p. 5-10.

[25] Tamizharasan T., Senthil Kumar N. (2012). Optimization of Cutting Insert Geometry Using DEFORM-3D: Numerical Simulation and Experimental Validation. International Journal of Simulation Modelling, vol. 11, no. 2, p. 65-76, D0l:10.2507/ IJSIMM11(2)1.200.

[26] Zorev, N.N. (1966). Metal Cutting Mechanics. Pergamon Press, Oxford.

[27] Zhao, Z., Hong, S.Y. (1992). Cryogenic properties of some cutting tool materials. Journal of Materials Engineering and Performance, vol. 1, no. 5, p. 705-714, Dol:10.1007/ BF02649252.

[28] Sandvik. Cemented Carbide, from http://www.sandvik.com, accessed on 2015-2-10. 